\title{
Fluid mechanics tests of separator-reheater turbines
}

\author{
Mikle Egorov ${ }^{1, *}$, Vyacheslav Suslov ${ }^{2}$ \\ ${ }^{1}$ Peter the Great St. Petersburg Polytechnic University, Polytechnicheskaya, 29, St. Petersburg, \\ 195251, Russian Federation \\ ${ }^{2}$ St. Petersburg State Technological University of Vegetable Polymers, ul. Ivana Chernykh 4, Russian \\ Federation
}

\begin{abstract}
The main aim of the current work is to increase operation efficiency and reliability of moisture separator-reheaters and turbines of NPPs. As the experience from MSR-500-1 operation showed the presence of large disperse moisture leads stops of the turbine. The high wetness level of steam downstream of separating devices observed since the first years of operation. Results from tests of the modernized separatorreheaters of the first unit at the Smolensk NPP with «Powervane» louvers developed by Balcke-Durr company are presented. Results from studies on the determination of wetness of the steam at the outlet from the separating part of the MSR-14, MSR-24, which demonstrate advantages of modernized construction are discussed. Modernization of separatorreheaters of the turbines TG-1, TG-2 resulted in eliminating nonuniformity of wetness over the perimeter and height of the steam space downstream the separation units. Success in modernization was caused by arranging separate outlets for moisture depositing at the walls, bottom of the inlet chamber. According to the results of the carried out studies an average value of the wetness at the outlet of the separation units was $0.6 \%$ which is close to the design value $0.5 \%$.
\end{abstract}

\section{Introduction}

Turbine units at nuclear power plant with reactors operating on saturated steam include intermediate moisture separator-reheaters (MSRs) [1, 2].

Single-case vertical apparatuses MSR-500-1 are composed [3]

- of the inlet chamber - in which wet steam flows from a high-pressure cylinder and separation of large-dispersed moisture from steam is carried out;

- $\quad$ separating parts - here subsequent separation of moisture occurs;

- superheating parts - here superheating of the dry steam to the temperature enabling operation of the low-pressure cylinder.

In the upper part of the MSR a separator is located and in the lower part there are two stages of superheating.

*Corresponding author: mikhail.yu.egorov@gmail.com 
One of the main requirements to the $\operatorname{MSR}[4,5]$ is effective [6-8] and reliable [9] operations of separating facilities [10] at every mode of operation of the power unit.

The high wetness level of steam downstream of separating devices observed since the first years of operation of the MSR. In our opinion and others [11], it is connected peculiarities of a design of the separating part, as a whole.

Studies undertaken earlier on the determination of wetness of the heated steam in MSR showed presence of large dispersion moisture [12]. Such effects were observed at the surface of the MSR opposite to the inlet receiver and occured during operation of the turbine unit at power of approximately $300 \mathrm{MW}$. With a growth of power these effects gradually increased. The studies allowed one to find zones of large dispersed moisture entrainment, the presence of which manifested itself as a decrease of temperature of the heated steam down to the values close to the saturation temperature. As the experience from MSR operation showed [13] the presence of large disperse moisture leads to damage in tubes distributing of the heating steam over the modulus of the first and the second stages of superheating and as a consequence to forced stops of the turbine plant $[14,15]$.

\section{Method of modernization of the separator part of the MSR}

The aim of modernizing MSR-500-1 is to increase operation efficiency and reliability of MSRs and turbine plants in general [16, 17]. Modernization of MSR-500-1 is based on replacing existing louvre separation devices by «Powervane» louvers developed by the Balcke-Durr company (BD). The scheme of steam motion in the inlet chamber, location of separation devices, and system of collectors were changed as well. Just the changing of the separation part of the MSR provided the improvement of operation of the louvers. The superheating part of the MSR was not modernized.

The project of modernization of MSR-500-1 was implemented at the Smolensk, Leningrad [18], and Kursk nuclear power plants.

The scheme of modernized MSR-500-1 is shown in Fig. 1. Steam enters the inlet chamber formed by a cover and a perforated sheet with conical holes of small depth for collecting and removing passing louvers of large disperse moisture at minimal hydraulic resistance. Selecting diameters of holes, their configuration and pitches between holes was based on results from simulating the process at the experimental rig [19]. Moisture deposited at the walls of the inlet chamber is removed separately (through holes 6) into outer circular collector. The steam is directed from the inlet chamber to 12 separation units of A, B, C, D, E, and F type with «Powervane» louvers representing the sets of wavy lines. These units are located in the annular space between the case and the outlet pipe and differ in a degree of perforation of metal sheets at the wet steam inlets to the units. This provides certain levelling of wet steam flows through the units. Due to such selecting the degree of perforation of the sheets [20], angular non-uniformity of specific steam flowrate at the inlet to the «Powervane» separation blocks is reduced. 


\section{EECE-2018}
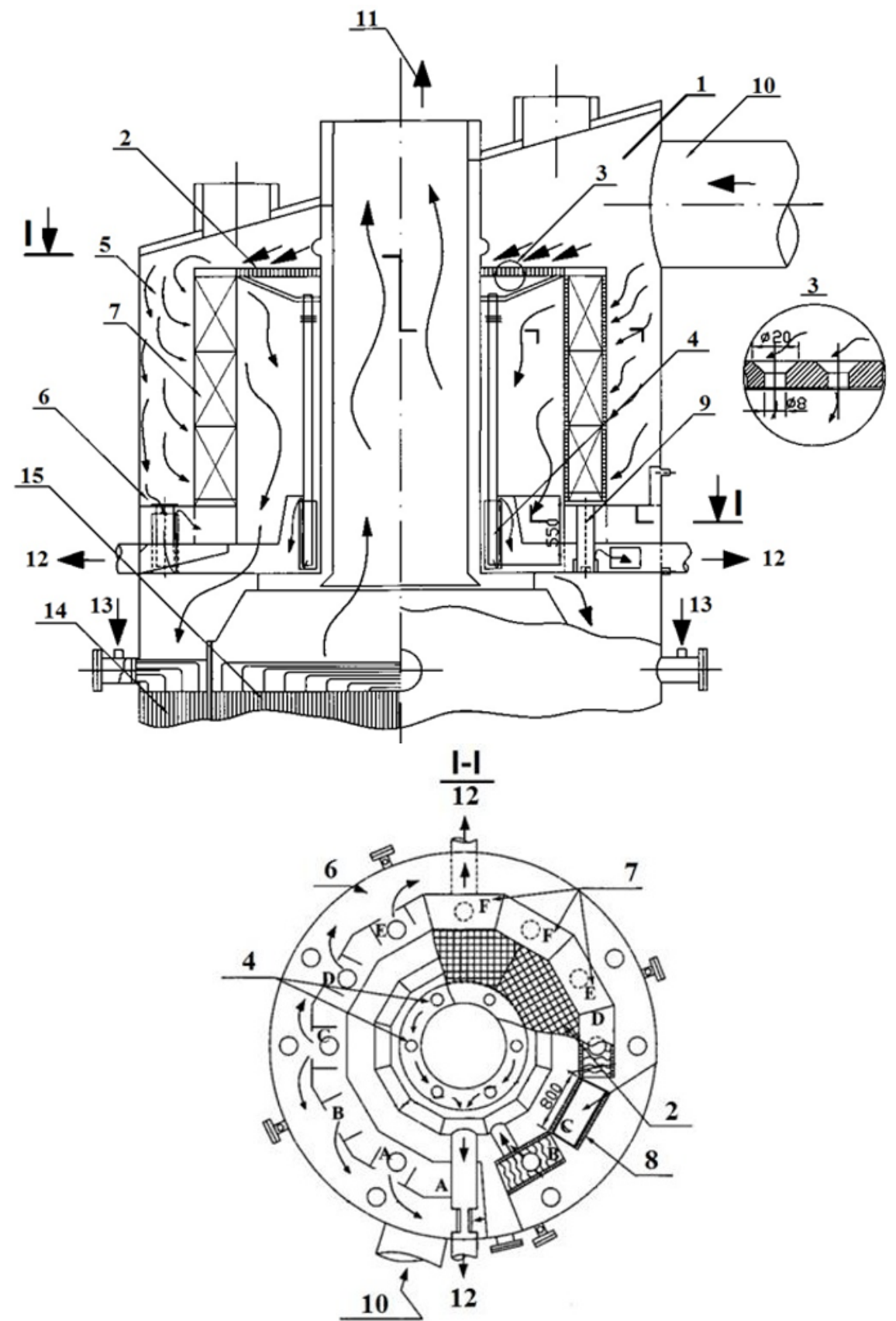

Fig. 1. General view of the modernized separation part of the MSR-500-1: (1) is inlet chamber; (2) is perforated sheet; (3) is holes; (4) is pipes for removing moisture separated at perforated sheet to inner annular header; (5) is removal of separate from walls of inlet chamber; (6) is holes of moisture removal from walls to outer annular header; (7) are separating blocks; (8) is inlet perforated sheet of the separating block; (9) are holes for separate removal from separation blocks into inner annular header; (10) is inlet of the wet steam from high-pressure cylinder; (11) is outlet pipe of MSR; (12) is removal of separate to the header; (13) is supply inlet of the heating steam of the second stage; (14) is modules of the first stage; (15) is modules of the second stage. 
Success in modernization of the MSR was to considerable extend caused by arranging separate outlets for moisture depositing at the walls [21] and bottom of the inlet chamber via a perforated sheet with holes. A reduction in the steam wetness at the inlet to the separation units and improvement of the flow distribution over the MSR perimeter decreased a load at the louvers and provided high efficiency of drying the steam flow [22].

\section{Results of tests of the modernized MSR}

In order to improve the efficiency of the separation part of MSR, they were upgraded based on replacing existing louvre separation devices by «Powervane» louvers developed by the Balcke-Durr company, changing the steam flow in the inlet chamber, changing the location of separation packages and collectors.

As a result, it became necessary to test modernized devices with subsequent analysis of the new experimental data obtained in the industrial conditions of Smolensk NPP. The results of tests of the modernized MSR-500-1 are described below. In the course of these tests the data on distribution over perimeter of the apparatus of the wetness of the separated steam were obtained.

\subsection{Determining wetness of the heated steam downstream of the separation units}

In the course of modernization of MSR at the Smolensk nuclear power plant a system of determining wetness of the heated steam at the outlet from the separation units with use of a throttle-colorimeter design.

Figure 2 shows a layout of steam extractions for determining steam wetness $y$ at the outlets from separation units. All pipes for extracting steam were inputted via the cover of the access-door. Sampling was carried out from the steam space and each sounder was supplied with three pipes located at a distance of $150 \mathrm{~mm}$ from each other, which allowed one to determine an average value of steam wetness after passing the separation unit. Steam sampling extractions Nos. 2 and 5 were located in front of separation units C and D at which a hydraulic lock was cut off and steam sampling extractions Nos. 3 and 4 were located near units B and E, respectively, equipped with hydraulic locks. The steam sampling outlet No. 6 located near the wall of the downcoming channel allowed one to control possible presence of draining liquid film at the wall. 


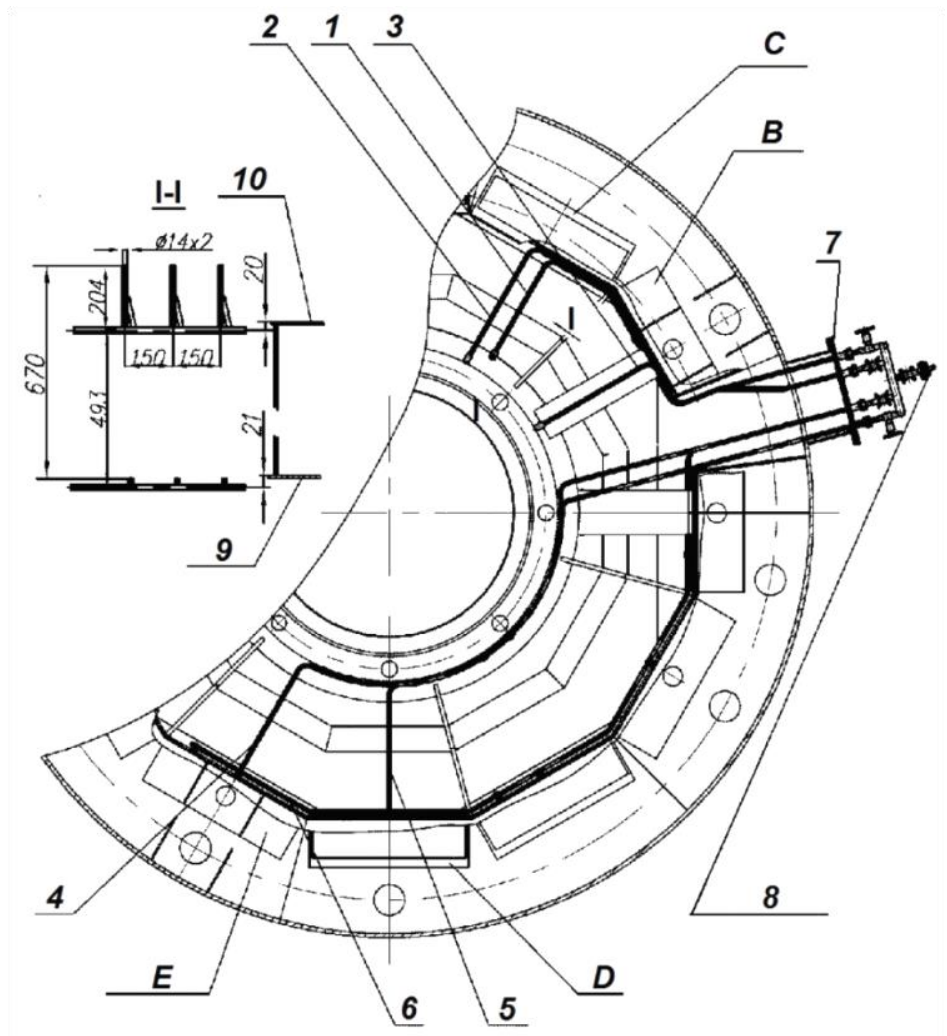

Fig. 2. Layout of the steam sampling units for determining wetness at the outlet from separation units. (1)-(6) are numbers of steam sampling blocks; (7) is cover of the access-door; (8) is connection with throttle-colorimeter; (9) and (10) are bottom and cover of the annular header.

To determine wetness of steam sought the most simple and convenient method was used, i.e. throttling wet steam from the two-phase region to the zone of superheated steam. At low pressures at the end of the process of a throttling enthalpy of steam practically does not depend on the pressure and, in general, on the temperature of the superheated steam.

Adiabatic nature of pressure in the throttle-colorimeter was secured with a steam jacket. The tests on the throttle-colorimeter carried out at the experimental rig showed that an absolute error of the device does not exceed $\pm 0.1 \%$ of wetness.

\subsection{Results of tests of the MSR and discussion}

In the course of the tests the values of wetness of the separated steam at two MSR-500-1 of the turbine units TG-1 and TG-2 were determined (Fig. 3, 4). Analyses of the data obtained shows that in two MSRs moisture is distributed uniformly over the perimeter of the apparatus and the value of wetness $y$ changes within the range of $0.5-0.7 \%$. In addition with use of steam sampling extractions Nos. 1 and 2, rather uniform distribution of wetness over the height of the steam space of the unit $\mathrm{C}$ was recognized. 


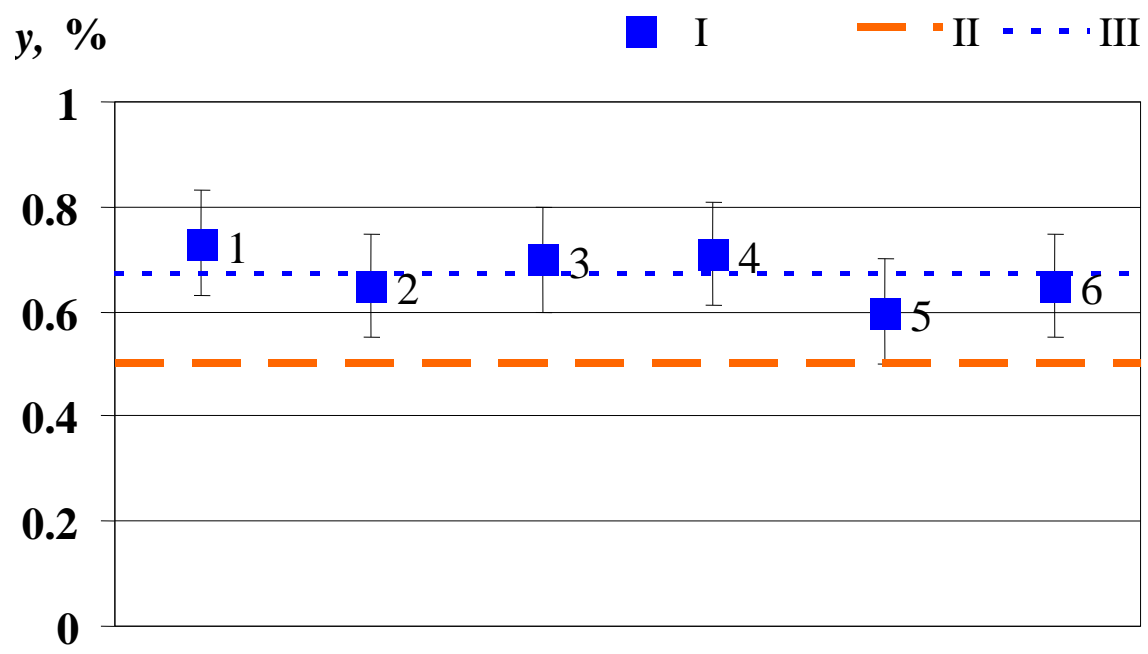

Fig. 3. Results of determining wetness of the separated, MSR-14: (I) is the experimental value, (II) is the design value, (III) is the average experimental value: (1) is the experimental value near channel wall, steam sampling unit No. 6; (2) is the experimental value at the separation unit E, steam sampling unit No. 4; (3) is the experimental value at the separation unit D, steam sampling unit No. 5; (4) is the experimental value at the separation unit B, steam sampling unit No. 3; (5) is the experimental value at the separation unit C, steam sampling unit No. $2 ;(6)$ is the experimental value at the separation unit C, steam sampling unit No. 1 .

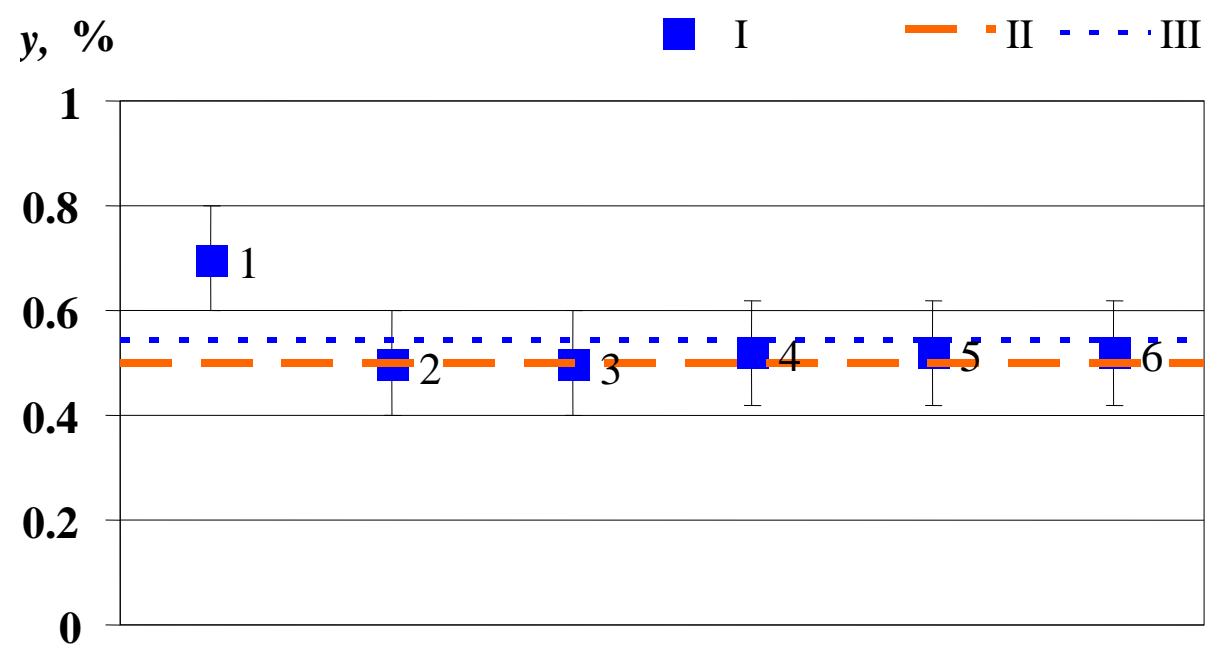

Fig. 4. Results of determining wetness of the separated, MSR-24: (I)-(III); (1)-(6) see the fig. 3.

The steam sampling extraction No. 6 located along the external wall of the downcoming channel practically did not show increased wetness which indicates the absence of the falling liquid.

According to the results of the carried out studies an average value of the wetness at the outlet of the separation units for each two units of the MSR was approximately $0.6 \%$ which is close to the design value. 


\section{Conclusions}

(1) The material includes new experimental data of humidity distribution of the separated steam on perimeter of the modernized MSR-500-1 at the outlet of the separation units for operating conditions of TG-1 and TG-2 of the power unit No. 1 of the Smolensk nuclear power plant.

(2) Modernization of moisture separator-reheater type MSR-500-1 including replacement of the separation units of the old design by those with «Powervane» louvers and changes in the scheme of motion of the heated steam resulted in eliminating nonuniformity of wetness over the perimeter and height of the steam space downstream the separation units making these values close to designed ones.

(3) The results of measuring wetness of the two turbine units TG-1 and TG-2 at the Smolensk nuclear power plant showed that after modernization a decrease in the distribution of wetness over the perimeter and height of the steam space downstream of separation units was reached and all the values measured were close to design ones $y \sim 0.5 \%$.

\section{References}

1. P. Peceny, M. Kolovratnik, Annals of Faculty Engineering Hunedoara - Intern. J. of Engineering, XI (4), 329-332 (2013)

2. J. Manabe, $22^{\text {nd }}$ Intern. Conf. on Nuclear Engineering ICONE22-30297, V02AT09A038 (2014)

3. V. Legkostupova, A. Sudakov, Matec Web of Conferences, Heat and Mass Transfer in the Thermal Control System of Technical and Technological Energy Equipment, 23, 01058 (2015)

4. G. Li, Ch. Yan, J. Wang, Annals of Nuclear Energy, 73, 537-546 (2014)

5. M. Le, J. Kim, J. Kim, H. Do, J. Lee, Nondestructive Testing and Evaluation, 33 (1), 35-44 (2018)

6. R. Rafee, H. Rahimzadeh, Iranian J. of Chemistry and Chemical Engineering, 29 (3), 95-108 (2010)

7. E. Narimani, S. Shahhoseini, Applied Thermal Engineering, 31 (2), 188-193 (2011)

8. H. Zhang, Q. Liu, B. Qin, H. Bo, Annals of Nuclear Energy, 75, 452-461 (2015)

9. X. Wang, P. Cheng, J. Xie, Z. Zhou, J. of Mechanical Science and Technology, 29 (8), 3531-3540 (2015)

10. F. Kavousi, Ya. Behjat, Sh. Shahhosseini, Chemical Engineering Research and Design, 91, 1212-1222 (2013)

11. Y. Liu, Z. Qu, Energy Procedia, 105, 1501-1506 (2017)

12. G. Venkatesan, N. Kulasekharan, S. Iniyan, Desalination, 329, 19-28 (2013)

13. V. Legkostupova, A. Sudakov, Thermal Engineering, 62 (3), 171-176 (2015)

14. M. Mirhoseini, M. Boroomand, Energy, 141, 1027-1037 (2017)

15. Z. Han, W. Zeng, X. Han, P. Xiang, Energies, 11, 2306 (2018)

16. L. Khomenok, P. Kruglikov, Y. Smolkin, K. Sokolov, Thermal Engineering, 59 (5), 352-358 (2012)

17. N. Davidenko, V. Solomeev, Thermal Engineering, 56 (5), 405-407 (2009)

18. M. Gotovskii, B. Fokin, M. Belen'kii, M. Lebedev, M. Blinov, M. Egorov, Thermal Engineering, 59 (2), 113-118 (2012) 
19. M. Egorov, Atomic Energy, 124 (2), 139-142 (2018)

20. J. Manabe, J. Kasahara, J. of Power and Energy Systems, 3 (2), 368-381 (2009)

21. J. Li, S. Huang, X. Wang, Chinese J. of Chemical Engineering, 15 (4), 492-498 (2007)

22. Z. Xiong, M. Lu, M. Wanga, H. Gu, X. Cheng, Annals of Nuclear Energy, 63, 138145 (2014) 